\title{
Recent Efforts Toward the Establishment of the Lonjsko Polje Geomagnetic Observatory
}

\author{
Igor MANDIĆ ${ }^{1}$, Eugen VUJIĆ ${ }^{2}$, Balázs HEILIG ${ }^{3}$, Izidor PELAJIĆ ${ }^{1}$, \\ and Davorka HERAK ${ }^{1}$ \\ ${ }^{1}$ Andrija Mohorovičić Geophysical Institute, Department of Geophysics, \\ Faculty of Science, University of Zagreb, Zagreb, Croatia; \\ e-mail: mandici@gfz.hr (corresponding author) \\ ${ }^{2}$ Faculty of Geodesy, University of Zagreb, Zagreb, Croatia; \\ e-mail: eugvujic@gmail.com \\ ${ }^{3}$ Geological and Geophysical Institute of Hungary, Budapest, Hungary; \\ e-mail: heilig.balazs@mfgi.hu
}

\begin{abstract}
More than ten years ago, the Geophysical Institute initiated the installation of a geomagnetic observatory in Croatia. Over the past decade, extensive surveys and studies have been conducted in order to determine the proper location for the observatory. Finally, in 2012, the observatory was established in Lonjsko Polje. This paper presents the first data recorded in the period 2012.5-2015.0. Also presented are the technical aspects and data processing techniques of this remotely operated observatory. Analysis of data quality and comparison with data from the surrounding INTERMAGNET observatories is discussed in detail. Although remote observatories cannot provide the ideal environment for magnetometers, the obtained results accentuate the potential of the new observatory to provide high-quality data. The establishment of this observatory paves the way for scientific and professional development of geomagnetism in Croatia.
\end{abstract}

Key words: geomagnetic observatory, magnetometers, variometer recordings, absolute measurements.

Ownership: Institute of Geophysics, Polish Academy of Sciences;

(C) 2016 Mandić et al. This is an open access article distributed under the Creative Commons Attribution-NonCommercial-NoDerivs license,

http://creativecommons.org/licenses/by-nc-nd/3.0/. 


\section{INTRODUCTION}

The geomagnetic field measured at the Earth's surface is a superposition of several contributions. More than $95 \%$ of the measured field originates from the electrically conductive fluid motions in the Earth's core (the main field). The lesser part is produced by the induced and remanent magnetization in the Earth's crust and upper mantle (the lithospheric field), and by timevarying current systems in the ionosphere and magnetosphere (the external field). The temporal changes of the field occur on a time scale ranging from a fraction of a second (i.e., pulsations) to millions of years (i.e., pole reversals). Short-term transient variations, from seconds to several days, arise mostly from the external field and associated internal induction effects. The long-term variations of the main field known as secular variation (SV) are noticeable on the annual time scales or longer.

Since the Earth's field is continuously subjected to temporal changes, only geomagnetic observatories can ensure continuous high quality longterm ( $>10$ years) measurements of the geomagnetic field and its variations. These long-term data provided by global observatory network are mandatory for studies of the Earth's core dynamics, geomagnetic jerks and for investigating the relationship between the long-term solar and geomagnetic activity. Ground observatories are an important complement to magnetic satellite data as they provide data from a different observation altitude and pure time series in contrast to satellite data containing both temporal and spatial variations. Observatory data help to better constrain satellite data and fill the gap between present and future satellite missions. Information from these different platforms offers the opportunity to exploit the geomagnetic field fully. Therefore, continuous magnetic observations are essential in order to obtain accurate and precise models. These models are used in scientific studies and have a great practical importance, e.g., for the renewal of magnetic maps, forecasting over a few years to predict declination for navigation purposes, applications in geology, mining, oil and gas exploration, etc.

There is also a regional need to have good observatory coverage, where observatories serve as base stations for geomagnetic surveys. Although Europe has the best observatory coverage, in some areas, the European network is still sparse for observing small-scale phenomena (for example, Cueto et al. 2003, Heilig et al. 2007, Verbanac et al. 2009). Furthermore, many observatories are threatened by magnetic disturbances caused by expanding cities and electric railway networks, and some of them will be forced to shut down operation or relocate.

Beside the global and regional need, there also exists national interest to install an observatory in Croatia. For more than 200 years, the elements of the Earth's magnetic field have been occasionally measured on the territory 
of Croatia (Markušić et al. 2012, Vujnović and Marić 2001). Under the auspices of the Hydrographic Office and for the needs of the Austro-Hungarian Navy, a magnetic observatory in Pula was operated from 1873 until the end of World War I (Mokrović 1948, Škreb 1912). Since then, Croatia has lacked observatory measurements on its territory. In the last decade, the Croatian Geomagnetic Repeat Station Network (CGRSN, 10 stations) together with the denser Croatian Geomagnetic Network for Field Mapping (CGNFM, 88 stations) has been established and surveyed (Brkić et al. 2006, Brkić and Šugar 2008, Vujić et al. 2011, Brkić et al. 2012). The purpose of these measurements is to renew the geomagnetic field information on Croatian territory and reveal the small-scale field variations produced by nearsurface magnetic rocks. To obtain the true value of the internal field at some epoch, it is necessary to eliminate transient variations from measurement. The removal of these variations is known as data reduction (Newitt et al. 1996). Reliability of data reduction greatly depends on the distance between the measurement site and the observatory, due to differences in the secular and transient variations at those two sites. In the absence of a national observatory, as an alternative solution the temporal reduction of CGRSN and CGNFM surveyed data was carried out using observatory data from neighbouring countries.

All the reasons mentioned above motivated us to establish an observatory in Croatia. In the search for a proper location, in 2003, V. Vujnović and his colleagues from the Geophysical Institute, Faculty of Science, made the first measurements of total field intensity over the mid-northern part of Croatia (Vujnović et al. 2004). The resulting analysis was conducted by calculating the declination, inclination, horizontal and total intensity using the global geomagnetic Comprehensive Model CM4 for the entire Croatian territory (Sabaka et al. 2004, Verbanac and Korte 2006). These results were used to understand the structure of the local field and find a suitable location for a new geomagnetic observatory. The new Croatian observatory requires an area with a low magnetic gradient to avoid crustal anomalies. After additional measurements and investigations, a location fitting all criteria had been determined (Vujić et al. 2009, Verbanac and Vujić 2012). Finally, all necessary instruments were purchased and the facilities for these instruments were constructed. Upon completion of the Lonjsko Polje Geomagnetic Observatory, its trial operation started in early 2012.

After almost a hundred years, the establishment of the observatory has renewed permanent monitoring of geomagnetic activity in Croatia. This will provide the foundation for the rapid development of geomagnetism, which has long been neglected, although it was one of the first geophysical disciplines in Croatia. 


\section{ABOUT THE OBSERVATORY}

\subsection{Observatory layout and instruments}

The new geomagnetic observatory is located in the area of the Lonjsko Polje Nature Park (central northern part of Croatia, Fig. 1). Based on exhaustive ground surveys, this location was chosen because it is an area without magnetic anomalies, it has a low field gradient, and is far enough from civilization noise (Verbanac and Vujić 2012). The location is a flat pasture-ground (of dimensions $600 \times 500 \mathrm{~m}^{2}$ ) more than $800 \mathrm{~m}$ from the main road (a narrow, low-traffic, non-asphalted road passes by one end of the pasture), and more than $1 \mathrm{~km}$ from the village. The distances from the nearest man-made disturbances are as follows: more than $9 \mathrm{~km}$ from $\mathrm{AC}$ load railway and highway, $55 \mathrm{~km}$ from the airport, $65 \mathrm{~km}$ from Zagreb, and $90 \mathrm{~km}$ from DC load railway. The observatory belongs to the group of "remote" observatories without permanent staff and is visited only for purposes of maintenance and absolute observations.

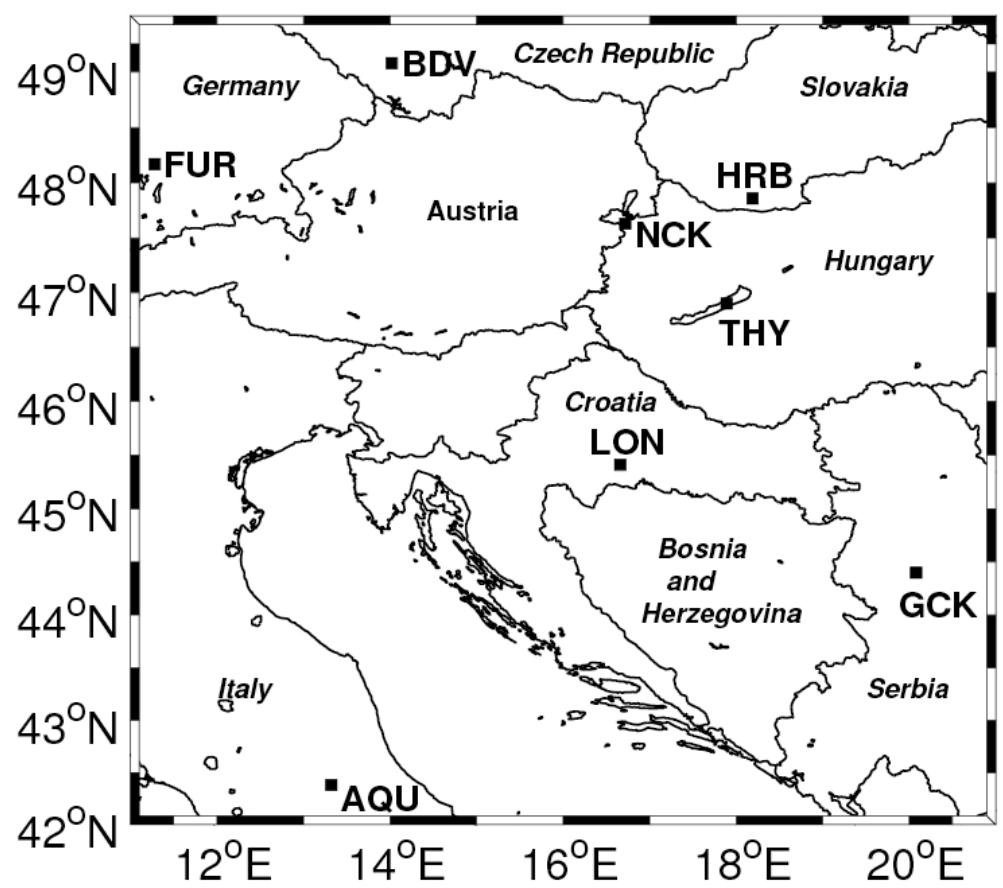

Fig. 1. Positions of the observatory in Lonjsko Polje (LON - provisional IAGA three-letter code) and surrounding INTERMAGNET observatories Budkov (BDV), Fürstenfeldbruck (FUR), Grocka (GCK), Hurbanovo (HRB), Nagycenk (NCK) and Tihany (THY), and former INTERMAGNET observatory L'Aquila (AQU). 


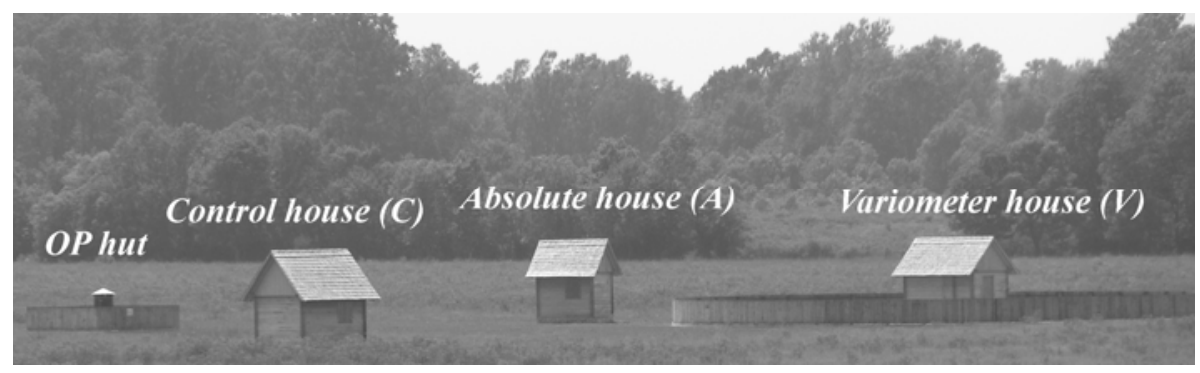

Fig. 2. Four structures of the LON observatory: OP (Overhauser Proton) hut, control house (C), absolute house (A), and variometer house (V).

Lonjsko Polje observatory (LON - provisional IAGA three-letter code) is composed of several huts (Fig. 2) built from non-magnetic materials, mostly oak, and using styrofoam for insulation to allay temperature effects. The huts' foundations and inner pillars are constructed from white cement. The power supply of the observatory comes from solar cells mounted on the roof of the control house (C). Although a power system based on both sun and wind energy would be a more reliable solution, unfortunately due to the Park's regulations, we could not obtain permission for a (small) wind turbine to design such a complex system. House $\mathrm{C}$ is the only structure allowed to have a relatively small amount of magnetic materials due to the $90 \mathrm{~m}$ distance from the huts that host the magnetometer electronics and their sensors.

The observatory operates several instruments, two scalar "Overhauser proton precession" magnetometers GSM-19 (manufacturer: GEM Systems, Canada) for measurement of the total intensity $(F)$, with $0.2 \mathrm{nT}$ absolute accuracy and $0.01 \mathrm{nT}$ resolution. For measurements of the absolute values of declination $(D)$ and inclination $(I)$ we use a Declination-Inclination magnetometer (DIM; manufacturer: MinGeo, Hungary). It is based on a Zeiss 010A geodetic theodolite with 1 second arc resolution converted into nonmagnetic, and equipped with a DI fluxgate magnetometer Model G, with $0.1 \mathrm{nT}$ resolution (manufacturer: Danish Meteorological Institute). The relative changes in inclination $(d I)$ and declination $(d D)$ are measured with a suspended dIdD magnetometer (manufacturer: GEM Systems, Canada). Beside variation recordings, the dIdD simultaneously provides total field recordings as well. Manufacturer specifications of this magnetometer are: $d I$ and $d D$ uncertainty is $\leq 1$ arcsec and $\leq 4$ arcsec rms, respectively, temperature drift is $<0.1 \mathrm{nT} /{ }^{\circ} \mathrm{C}$ and the long-term drift is $<2 \mathrm{nT} /$ year. Furthermore, since December 2012, the observatory also hosts a Ukrainian three-axial fluxgate magnetometer LEMI-035 (manufacturer: Lviv Centre of Institute for Space Research). It is low-noise $(<10 \mathrm{pT}$ at $1 \mathrm{~Hz})$ with $1 \mathrm{pT}$ resolution and temperature drift $<0.5 \mathrm{nT} /{ }^{\circ} \mathrm{C}$, installed in the framework of the EU FP7 
PLASMON Project (Heilig et al. 2013a; http://plasmon.elte.hu/home.htm) in cooperation with the Tihany Observatory (MFGI - Geological and Geophysical Institute of Hungary).

The dIdD instrument is recording continuously in the variometer house (V), the GSM-19 is placed in the OP (Overhauser Proton) hut (Fig. 2), while absolute DI observations are carried out with the DIM on the absolute pillar standing inside the absolute house (A). A second scalar magnetometer is used occasionally for measurements of total field values on pillar A. This pillar is the location where all observatory measurements are reduced to. Its WGS- 84 coordinates are $45^{\circ} 24^{\prime} 29^{\prime \prime} \mathrm{N}, 16^{\circ} 39^{\prime} 33^{\prime \prime} \mathrm{E}$, and altitude is $95 \mathrm{~m}$ above sea level. To achieve better temperature stability, the dIdD sensor is enclosed in a wooden box padded with $0.3-\mathrm{m}$ thick styrofoam panels. Currently, we do not have active temperature control (cooling/heating) in house $\mathrm{V}$, but comparison between temperature recordings inside (temperatures of dIdD electronic and sensor) and outside house $\mathrm{V}$ indicate that diurnal temperature changes inside house V are significantly lower (around 80\%). Daily temperature variation around the sensor is kept within several degrees, with average amplitude of $1.2 \pm 0.7^{\circ} \mathrm{C}$, and $2.6 \pm 1.4^{\circ} \mathrm{C}$ for electronic. Since $\mathrm{dIdD}$ is based on a scalar magnetometer insensitive to temperature variation, most of the drift originates from the thermo-mechanical deformation of the spherical coil system around the sensor. According to technical specifications and temperature around the sensor, we assume there is no significant $(<0.5 \mathrm{nT})$ temperature drift superimposed to daily magnetic data. The LEMI sensor is buried $1 \mathrm{~m}$ under the ground and its electronics unit and the data acquisition unit (DAQ) developed at MFGI (Merényi et al. 2013) are mounted in a shelter on the fence that surrounds house V. During the installation of the LEMI, we made sure that its sensor was far enough from the dIdD, which produces strong deflection fields during operation and could cause interference. Average daily temperature changes for the LEMI sensor and electronics are $0.07 \pm 0.04^{\circ} \mathrm{C}$ and $6.8 \pm 5.6^{\circ} \mathrm{C}$, respectively. Unfortunately, due to the lack of suitable infrastructure, we could not provide a temperaturestable environment for the LEMI electronics, but luckily for the purposes of geomagnetic pulsation studies, temperature stability is a less important factor (Heilig et al. 2013a). Both variometer systems are also subdued to long-term annual temperature changes around $15-20^{\circ} \mathrm{C}$, and these drifts are eliminated by a standard procedure - baseline calibration (Jankowski and Sucksdorff 1996).

In house $\mathrm{C}$, the main data acquisition system is located, together with accompanying modules (GPS antenna, RS and A/D converters) for the collection and storage of data from the magnetometer systems in OP hut and house V. The main DAQ is basically the same as the LEMI's DAQ, only it has different operating settings. Through Internet communication provided by mo- 
bile Internet, all data are uploaded to the server of the Geophysical Institute in Zagreb every hour, while the LEMI data is also uploaded to the PLASMON server of the Tihany Observatory every $15 \mathrm{~min}$. Both acquisition systems are connected via Ethernet to a third industrial PC, which serves as an in situ server for storing the data, and which can be used for dIdD data logging in case of malfunction of the main DAQ. This PC has somewhat better performance than those used for primary data acquisition, thus enabling us remote access to LON through the Internet provided by a second modem. This allows us to check the dIdD and LEMI systems remotely, and, if necessary, modify the configuration settings, or reach data manually if there is a problem with the main Internet connection.

\subsection{Significant events and notes}

After completion of the construction works in October 2011, the observatory was ready for furnishing, installation of the instruments and power supply system. In the spring of 2012, preparations were made for magnetometer installation. By May, the total field and variometer measurements had started. By July 2012, we had determined the azimuth bearing necessary for the absolute DI observations, and conducted the required self-training since we did not have skilful observers for the purpose of these observations. In the second half of 2012, some additional construction works had been performed, and consequently, the data were contaminated or missing for several days: 5 July, 17-19 July, 19-25 October, and 12 December 2012. In 2013, from 1 April to 10 July, we had a great loss of data due to the river flooding. The dIdD electronic unit was damaged and had to be replaced, while minor repairs were made on the LEMI DAQ. After refurnishing the observatory, measurements had continued. Then we suffered another data loss in the period from 23 November to 4 December 2013, due to problems with data logging. In 2014, the main system operated without major interruptions, except for eleven days in December (3-5, 7-11, and 17-19 Dec) when the solar battery chargers malfunctioned and were eventually replaced with new ones. During these interruptions, the secondary system (LEMI) operated continuously.

On two occasions, in November 2012 and October 2014, we experienced problems with DIM caused by the humid environment. Due to condensed water droplets inside the theodolite, the minute and second circle scales became fuzzy, and accurate readings were not possible.

Until the autumn of 2013, one of the authors of this paper performed absolute observations. During this time, DI observations were performed twice a month when possible. Since it is a two-hour drive to the observatory, observations once a week were not possible due to the lack of sufficient finan- 
cial support for these trips. This was resolved by contracting a local resident to conduct regular absolute observations. Since October 2013, absolute observations have been conducted once a week, although skipping some weeks. The reason is that, sometimes, the observatory is unreachable because of the increased water level of the local rivers, hinterland waters and mud. The last years have been extremely hydrologically inconvenient, and, moreover, the problems with water around the site of the observatory are mostly caused by improper maintenance of the local riverbanks. Persons responsible have been notified, and, hopefully, this issue will be solved in the near future.

\section{ACQUIRED DATA}

\subsection{Handling the recordings}

For the sake of completeness, we will describe the process of data production. Except for the LEMI with $128 \mathrm{~Hz}$ data rate, all other recording systems are set to 5 second sampling. In the case of dIdD, this means that every 5 seconds, we have four biased total field readings and the unbiased ambient field reading, all required for deriving variation of inclination and declination (Alldredge 1960, Hegymegi et al. 2004). The Gaussian low-pass filter is applied on the 5 second raw variation data and the total field recordings in order to obtain the standard INTERMAGNET (http://www.intermagnet.org/) minute means (St-Louis 2011). The final minute data are calibrated to the absolute level using adapted base values (see Section 3.2) for declination and inclination, while total field is corrected for the offset between pillars A and V. All other components are then calculated from $D, I$, and $F$ values.

Raw samples from the LEMI magnetometer are automatically filtered by two successive Gaussian digital filters embedded in the DAQ software. The first filter produces $16 \mathrm{~Hz}$ data, while the second produces $1 \mathrm{~Hz}$ data from which the standard minute means are obtained. In case the dIdD data are missing, they are complemented with baseline corrected LEMI data. This only occurred in 2014, because in 2013 after the flood period, we had temporary problems with the mechanical stability of the LEMI sensor. Consequently, the baselines drifted around $200 \mathrm{nT}$ (or more, depending on which component is considered) and they could not be properly corrected, at least not with the rare and irregular observations in 2013, as presented in Fig. 3. The same observations used to derive $\mathrm{dIdD}$ base values are also used to find LEMI base values. To fit continuous baselines over spotted values, for both variometer systems, the smoothing spline technique is used (De Boor 1978).

Later, based on visual inspection of the data and comparison with data from surrounding observatories (Fig. 1), artificial disturbances and spikes are identified and removed. Finally, the FMI algorithm (Menvielle et al. 1995) is 


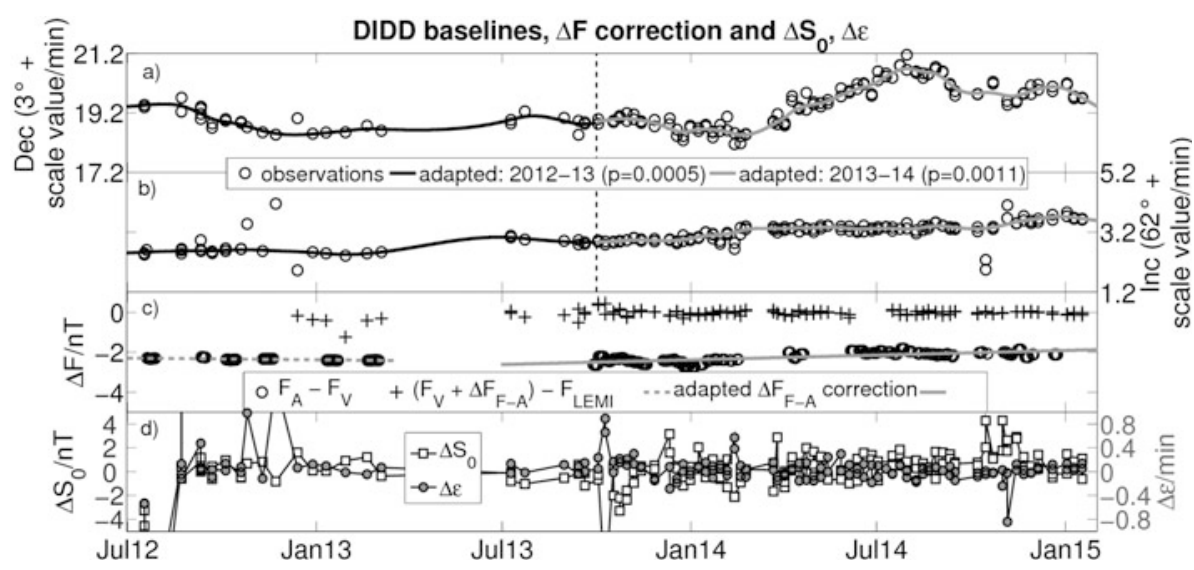

Fig. 3: (a) and (b): dIdD observed and adapted baselines 2012.5-2015.0 for $D$ and $I$; (c): Total field offset between pillars $\mathrm{A}$ and $\mathrm{V}$ together with residuals $\left(F_{\mathrm{V}}+\right.$ $\left.\Delta F_{F-\mathrm{A}}\right)_{\mathrm{SCALAR}}-\left(F_{\mathrm{LEMI}}\right)_{\mathrm{VECTOR}} ;(\mathrm{d})$ : Quality parameters $\Delta S_{0}$ and $\Delta \varepsilon$ obtained from DI observations (see text for details).

applied to produce local geomagnetic activity indices $K$ with $350 \mathrm{nT}$ as the lower $K=9$ limit (Bartels et al. 1939, Matsushita and Campbell 1967).

The $K$ index is a three-hour range index designed to measure the irregular deviations from the daily solar regular $\left(S_{R}\right)$ variation of the geomagnetic field. Based on the difference between the highest and lowest deviation from $S_{R}$ within three-hourly interval, the $K$ index is determined. The (dimensionless) logarithmic scale is used to obtain the index value (from 0 to 9) based on the amplitude of the disturbance in a three-hourly interval. In this way the deviations corresponding to the lower limit for $K=9$ are 100 times larger than those corresponding to the upper limit for $K=0$ and these limits gave a reasonable frequency distribution for the nine values. However, due to statistical reasons it is also desirable to have indices on a linear scale. Therefore, along with calculation of $K$ indices, a reconversion into equivalent linearly scaled $a k$ index is done and a daily index, $A k$, or equivalent daily amplitude, is determined as average of eight $a k$ values. The $a k$ and $A k$ are expressed in units of nT. For more details on indices, see the textbook (Matsushita and Campbell 1967).

\subsection{Absolute measurements and baselines}

For the above-mentioned reasons (Section 2.2), we decided to construct two baseline segments to correct dIdD variation recordings to the absolute level. To construct the first curve, we used observations from July 2012 to November 2013, a period of sparse and irregular observations. The second curve was obtained using observations from September 2013 to February 
2015. Thus, we calculated two baseline segments that share observations in September and October 2013, which were joined at day 1 October 2013 (black and grey lines, panels (a) and (b) in Fig. 3). This way, we obtained curves suitable to fit on periods of dense and sparse observations. The adapted baselines were obtained using the smoothing spline technique, where the smoothing parameter $p$ was chosen as a function of the average sampling period $h$ according to relation $p=1 /\left(1-h^{3} / 0.6\right)$ (De Boor 2003). The average sampling period $h$ was obtained as the total number of days for each spline segment per number of observation days and multiplied by 2 , since two sets are usually performed during an observation day. The base values obtained from absolute observations and the adapted baselines for declination and inclination are presented in Fig. 3a, b.

Legitimate procedures also include correction of the dIdD scalar reading to pillar A. For this purpose, a second scalar magnetometer is occasionally installed on pillar A, and continuous measurements are taken for several days. The observed daily mean differences between total intensity on pillars $\mathrm{A}$ and $\mathrm{V}$ (black circles in Fig. 3c) indicate a slow decrease from $-2.3 \mathrm{nT}$ (July 2012) to $-2.5 \mathrm{nT}$ (September 2013) and since then we have a slow increase up to $-2.1 \mathrm{nT}$ to the end of 2014. Two linear fits are used to obtain scalar baseline from these observations, one for the period from July 2012 to April 2013 (grey dashed line in Fig. 3c), and the other for the period from July 2013 to January 2015 (grey line in Fig. 3c). Fitted vales $\left(\Delta F_{F-\mathrm{A}}\right)$ were then used to reduce dIdD scalar readings to pillar A. Also presented is the difference between the dIdD total field reduced to pillar $\mathrm{A}\left(F_{\mathrm{V}}+\Delta F_{F-\mathrm{A}}\right)$ and the total field calculated from component values recorded by Lemi $\left(F_{\text {LEMI }}\right)$ during the time of observations (black crosses in Fig. 3c).

The DI measurement protocol enables us to determine "zero-field" offset $\left(S_{0}\right)$, horizontal $(\delta)$, and vertical $(\varepsilon)$ collimation misalignment angles between the axis of the fluxgate sensor and the optical axis of the theodolite (Lauridsen 1985). Quantities $S_{0}$ and $\varepsilon$ can be calculated separately from declination and inclination readings, and if the instrument is well adjusted, the residuals $\Delta S_{0}=S_{0}{ }^{D}-S_{0}{ }^{I}$ and $\Delta \varepsilon=\varepsilon_{D}-\varepsilon_{I}$ during one observational set is not expected to exceed $\pm 2 \mathrm{nT}$ and \pm 0.1 arc minutes, respectively. In the cases of high quality observations, the scatter of these values should be low. In Fig. $3 \mathrm{~d}, \Delta S_{0}$ and $\Delta \varepsilon_{0}$ are shown for all $D$ and $I$ observations presented in the upper subplots. Having rejected low quality observations (11\% of total), the calculated average residuals were $\Delta S_{0}=0.25 \pm 0.95 \mathrm{nT}$ and $\Delta \varepsilon=0.03$ \pm 0.11 arc minutes.

\subsection{Daily means: 2012.5-2015.0}

Figure 4 shows the daily mean values calculated from the standard minute averages calibrated to the absolute level using adapted base values and 


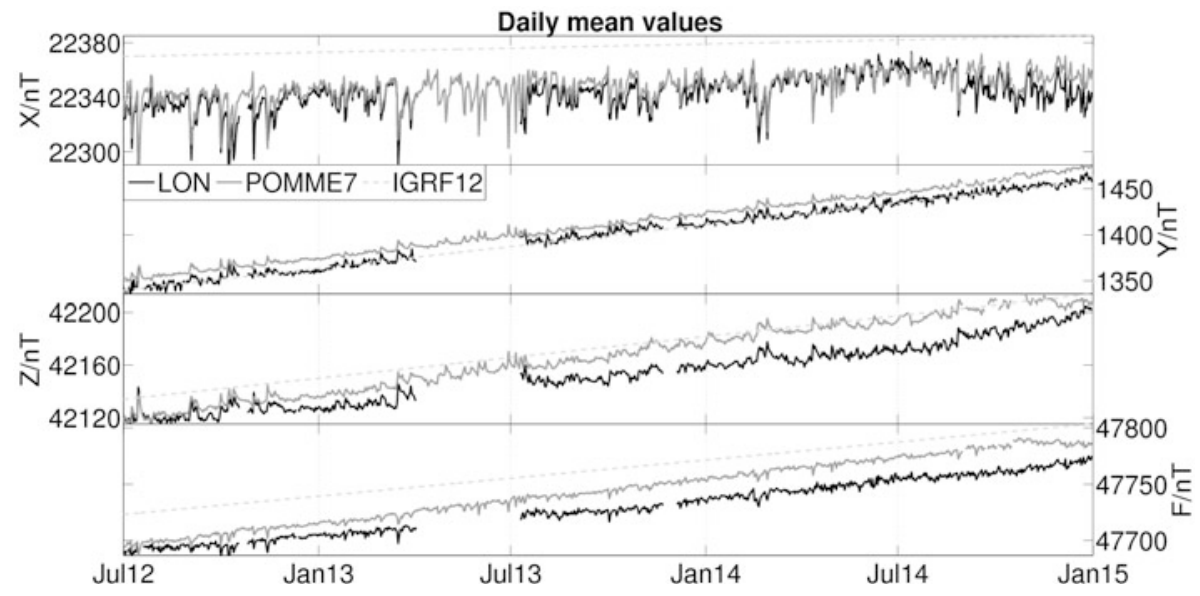

Fig. 4. The daily mean values observed in LON together with values predicted by IGRF12 and POMME7 model.

$\Delta F_{\mathrm{A}-\mathrm{V}}$ correction, as presented in Fig. 3. Generally, the values of all elements were increasing during the 2012.5-2015.0 period, where $X$ is the most variable component but with the smallest long-term change. Numerical values centred to epochs 2012.75 and 2014.75 are: 22331 and $22349 \mathrm{nT}$ for $X$, 1353 and $1447 \mathrm{nT}$ for $Y, 42124$ and $42185 \mathrm{nT}$ for $Z, 47697$ and $47762 \mathrm{nT}$ for $F$. Additionally plotted were the values predicted by IGRF12 (Thébault et al. 2015) and POMME7 (http://www.geomag.org/models/pomme7.html). IGRF12 is the main field model with spherical harmonic expansion (SHE) up to degree and order 13, while POMME7 model accounts the internal part up to degree and order 133, and a daily varying external field of degree and order 1 (Olsen et al. 2006).

The main field model slightly overestimates the observed values, about several tens of nT, except in $Y$ component, where we have good overlapping. The secular trend is also well predicted. Except in $Y$, the values obtained with POMME7 model are closer to those observed in absolute sense, although we have an overestimation of the secular trend in $Z$ and consequently in total intensity $F$. A similar comparison was done also with POMME8 (http://geomag.org/models/pomme8.html, same parameterization as version 7), WMM2010 - the main field model SHE up to degree/order 12 (Maus et al. 2010), and EMM2010 - the main and crustal field model SHE up to degree/order 720 (Maus 2010). The secular trend of $Z$ component obtained with POMME8 is much more consistent with observations, but, on the other hand, we obtain an underestimation of secular change in $X$ component. Comparison with WMM2010 gives similar results as in the case of IGRF12, 
while in the case of EMM2012, the observed components are underestimated by approximately $25 \mathrm{nT}$. This analysis leads us to conclude that LON data are consistent with modelled data up to the model accuracy. However, existing differences both in absolute values and the secular trends not resolved by any of the existing models point to the necessity of permanent observations at LON.

\section{RESULTS AND DISCUSSION}

\subsection{Total field differences between the pillars}

The nonparallel mean total field vectors at two relatively nearby sites can cause time variations in the total field gradient between the two sites, even if the external field variations are homogeneous over the investigated area (Shirman and Ginzburg 2004). In this case study, we have two total field gradiometers: one that measures the total field differences between $\mathrm{A}$ and $\mathrm{V}$ sites, and one that measures between A and OP sites. Let us firstly consider the A-V gradiometer. Suppose that at some time instant the local total field intensities (without the external field contribution) over $\mathrm{A}$ and $\mathrm{V}$ sites are $\left|\boldsymbol{B}_{\mathrm{A}}\right|$ and $\left|\boldsymbol{B}_{\mathrm{V}}\right|$, respectively, the external field intensity is $\left|\boldsymbol{B}_{e}\right|$, and the gradiometer reading is $\Delta F=F_{\mathrm{A}}-F_{\mathrm{V}}=\left|\boldsymbol{B}_{\mathrm{A}}+\boldsymbol{B}_{e}\right|-\left|\boldsymbol{B}_{\mathrm{V}}+\boldsymbol{B}_{e}\right|$. If one could assume that $\left|\boldsymbol{B}_{e}\right|<<\left|\boldsymbol{B}_{\mathrm{A}}\right|,\left|\boldsymbol{B}_{e}\right|<<\left|\boldsymbol{B}_{\mathrm{V}}\right|$, and that the external field $\boldsymbol{B}_{e}$ (and induced counterpart) is homogeneous over the $\mathrm{A}$ and $\mathrm{V}$ sites, then $\Delta F$ can be written as:

$$
\Delta F \approx\left(B_{\mathrm{A}}-B_{\mathrm{V}}\right)+\boldsymbol{B}_{e} \cdot\left(\frac{\boldsymbol{B}_{\mathrm{A}}}{B_{\mathrm{A}}}-\frac{\boldsymbol{B}_{\mathrm{V}}}{B_{\mathrm{V}}}\right) .
$$

From Eq. 1 it can be concluded that the gradiometer readings are not time-dependent if the differences $B_{\mathrm{A}}-B_{\mathrm{V}}$ are constant, and either: (a) the external field is perpendicular to the difference of the local total field unit vectors; (b) the local total fields are parallel; or (c) the scalar product on the right side of Eq. 1 is constant. In a case when the gradiometer readings are time-dependent, Eq. 1 can be written in the following form:

$$
\Delta F(t)=a+b \cdot \Delta X(t)+c \cdot \Delta Y(t)+d \cdot \Delta Z(t) .
$$

Here, the external field was divided into two parts: $X, Y$, and $Z$ quietnight values, and variations $\Delta X(t), \Delta Y(t)$, and $\Delta Z(t)$. The latter were derived as the differences between the $X, Y$, and $Z$ dIdD recordings and their quietnight baselines (Yamazaki et al. 2011). Those baselines were derived as the mean of six night-time values (i.e., values at 22:00, 23:00, 24:00, 01:00, 02:00, and 03:00 LT). 

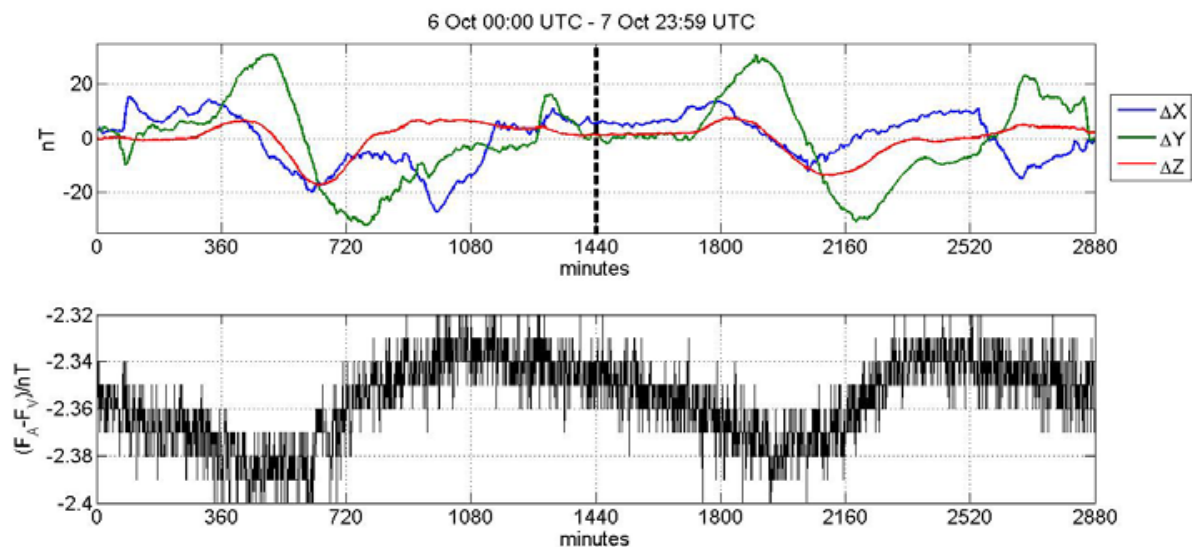

Fig. 5. Top: The $X, Y$, and $Z$ time variations during two days in 2012. Bottom: The A-V gradiometer recordings during the same two days. The days are separated by the vertical dashed line.

The "constant" term $a$ in Eq. 2 depends on $B_{\mathrm{A}}-B_{\mathrm{V}}$ and on the quiet-night values (due to the nonparallel local total field vectors), so this term is constant only during those time intervals when $B_{\mathrm{A}}-B_{\mathrm{V}}$ and the quiet-night values are approximately constant. That is why this analysis was conducted only for the quiet days $(K p \leq 2)$, i.e., using the one-day minute averages. The term $a$ in Eq. 2 was derived by multiple regression analysis (Montgomery et al. 2012). The same procedure was used for A-OP gradiometer.

In Fig. 5, an example is given of the $\mathrm{A}-\mathrm{V}$ gradiometer recordings. A small but clear time-dependence can be noticed, although within $0.1 \mathrm{nT}$. The time variations $\Delta X, \Delta Y$, and $\Delta Z$ are also given for visual comparison. One can notice that higher variability of the gradiometer data occurs during higher variability of the external field variations. In Fig. 6, the results for parameter $a$ are presented, for both the A-V and A-OP gradiometers, respectively. The mean values during the interval July 2012 to February 2013 were $a_{\mathrm{A}-\mathrm{V}}=(-2.3 \pm 0.1) \mathrm{nT}$ and $a_{\mathrm{A}-\mathrm{OP}}=(2.1 \pm 0.1) \mathrm{nT}$. The distances between pillars $\mathrm{V}$ and $\mathrm{A}$, and the OP hut are more than $25 \mathrm{~m}$, where the northernmost point of measurement is pillar $\mathrm{V}$, while $\mathrm{OP}$ is the southernmost point. This result verifies that the observatory is located on a homogeneous, low gradient terrain (Jankowski and Sucksdorff 1996). If we simply average the differences between total field recordings during all the days when PPM performed measurements on pillar A, we obtain practically the same results (well within the absolute accuracy of the scalar magnetometer). This means it is sufficient to use the first term in Eq. 1 only to determine $\Delta F_{\mathrm{V}-\mathrm{A}}$. This difference is used to reduce the dIdD total field recordings to pillar A. 


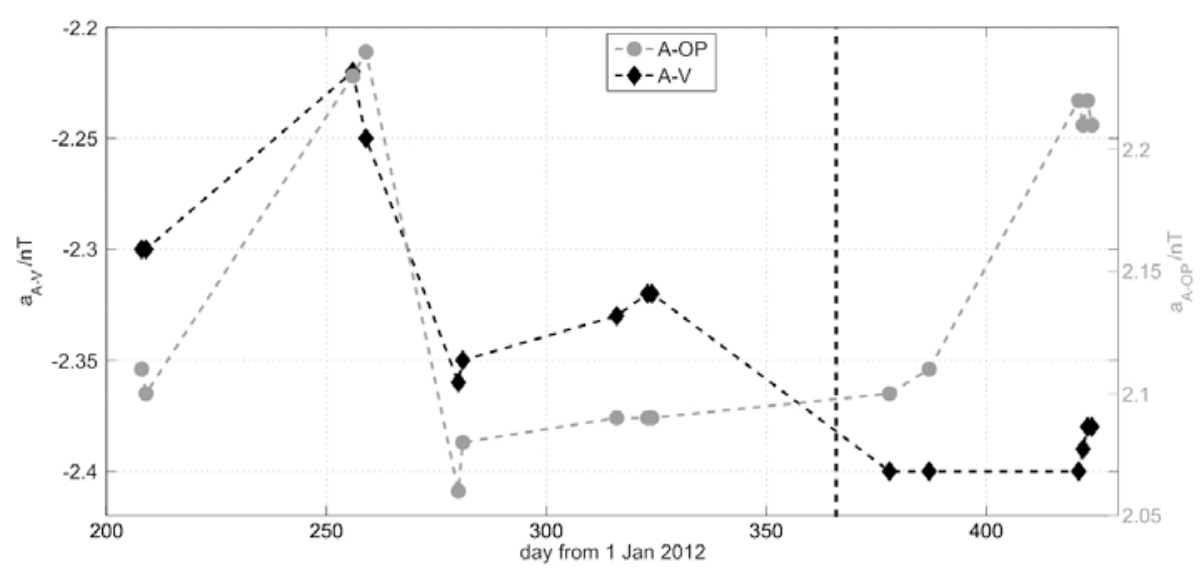

Fig. 6. Parameter $a$ from Eq. 2 estimated for quiet days, during the interval from July 2012 to February 2013, for A-V gradiometer (left axis) and A-OP gradiometer (right axis). The vertical dashed line represents the end of 2012 .

\subsection{Comparison with the data from nearby INTERMAGNET observatories}

In order to investigate the data quality and representativeness of LON geomagnetic activity index $K$ (latter denoted as $K_{\mathrm{LON}}$ ), we analysed the differences of time series between LON and nearby observatories following the idea from Vujić et al. (2009). The analysis was done for the period from 1 July to 31 December 2012. This period was chosen due to the fact that while this paper was being prepared, only definitive data from 2012 were available for most of the nearby INTERMAGNET observatories (IMOs). IMOs used in this study, together with their geographic and geomagnetic coordinates (according to IGRF12 model), are listed in Table 1. For the investigated period, $5 \%$ of the data were missing. The majority of the data gaps occurred at LON. Average correlation coefficients of raw minute time series calculated for LON and nearby observatories and for all components, were higher than 0.95 , ranging from 0.955 for LON and BDV up to 0.989 for LON and THY.

To eliminate the time-dependent contribution that originates from annual changes, the minute data for each day were centred to zero and then the differences between LON and GCK, THY, HRB, FUR, and BDV were calculated for $X, Y, Z$, and $F$. These differences for all the 184 days were divided in 1472 three-hour subintervals, and their standard deviations calculated, each corresponding to a specific $K_{\text {LON }}$ value. Finally, the average standard deviation $\left(\sigma_{\text {avg }}\right)$ for each $K_{\mathrm{LON}}$ was obtained. Figure 7 shows the obtained results. For better visual appearance, logarithmic scaling is used to present the 
Table 1

Averaged three-hour standard deviations of $\dot{X}, \dot{Y}, \dot{Z}$, and $\dot{F}$ at geomagnetically quiet periods $\left(K_{\mathrm{LON}} \leq 2\right)$

\begin{tabular}{|c|c|c|c|c|c|c|c|c|}
\hline \multirow[b]{2}{*}{$\begin{array}{c}\text { Observ- } \\
\text { atory }\end{array}$} & \multicolumn{2}{|c|}{ Geographic } & \multirow[b]{2}{*}{$\begin{array}{c}\sigma(\dot{X}) \\
{[\mathrm{nT} / \mathrm{min}]}\end{array}$} & \multirow[b]{2}{*}{$\begin{array}{c}\sigma(\dot{Y}) \\
{[\mathrm{nT} / \mathrm{min}]}\end{array}$} & \multirow[b]{2}{*}{$\begin{array}{c}\sigma(\dot{Z}) \\
{[\mathrm{nT} / \mathrm{min}]}\end{array}$} & \multirow[b]{2}{*}{$\begin{array}{c}\sigma(\dot{F}) \\
{[\mathrm{nT} / \mathrm{min}]}\end{array}$} & \multicolumn{2}{|c|}{ Geomagnetic } \\
\hline & $\begin{array}{l}\text { Lat. } \\
\text { [dec. de }\end{array}$ & $\begin{array}{l}\text { Long. } \\
\text { grees] }\end{array}$ & & & & & $\begin{array}{l}\text { Lat. } \\
\text { [dec. }\end{array}$ & $\begin{array}{l}\text { Long. } \\
\text { degrees] }\end{array}$ \\
\hline GCK & 44.40 & 20.80 & 0.22 & 0.23 & 0.08 & 0.15 & 42.86 & 102.49 \\
\hline $\mathrm{LON}$ & 45.41 & 16.66 & 0.25 & 0.19 & 0.08 & 0.12 & 44.53 & 98.95 \\
\hline THY & 46.90 & 17.54 & 0.27 & 0.23 & 0.08 & 0.12 & 45.83 & 100.22 \\
\hline HRB & 47.86 & 18.19 & 0.26 & 0.23 & 0.13 & 0.17 & 46.66 & 101.18 \\
\hline FUR & 48.16 & 11.28 & 0.23 & 0.24 & 0.10 & 0.14 & 48.12 & 94.68 \\
\hline BDV & 49.08 & 14.02 & 0.24 & 0.24 & 0.08 & 0.17 & 48.54 & 97.67 \\
\hline
\end{tabular}

Notes: Geomagnetic observatories are listed by their geographic or geomagnetic latitudes, in ascending order. Geomagnetic coordinates are calculated using IGRF12.
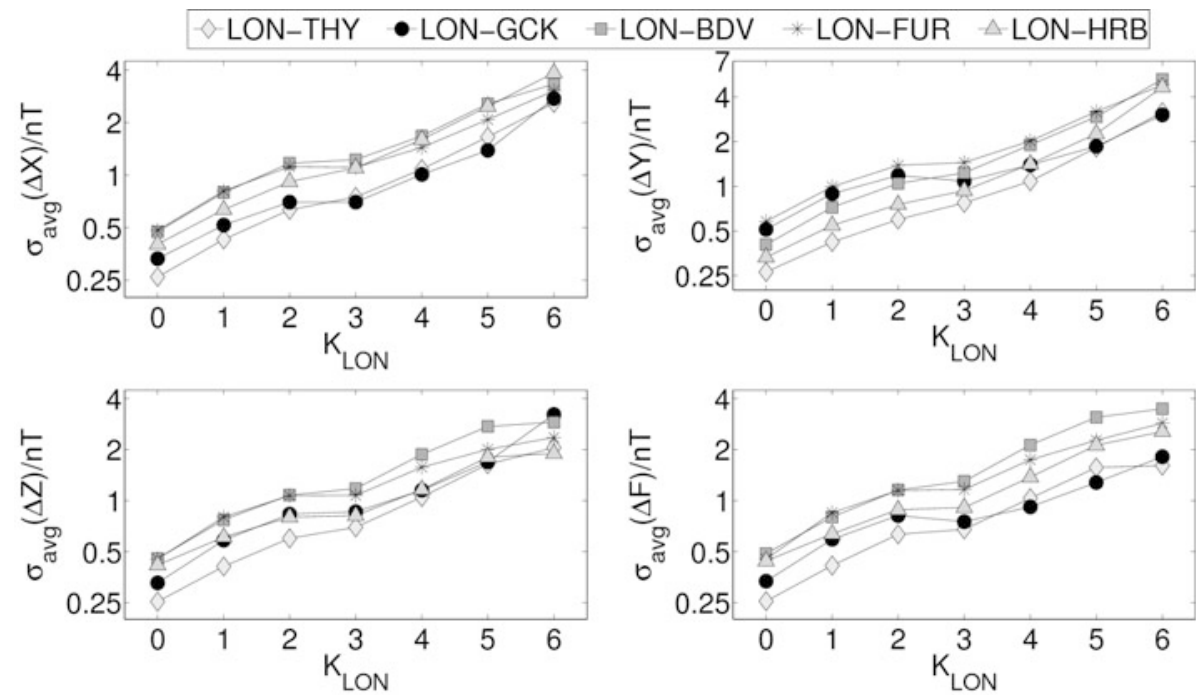

Fig. 7. Mean three-hour standard deviations of the differences between LON and INTERMAGNET observatory time series (1 July to 31 December 2012) versus geomagnetic activity index $K_{\mathrm{LON}}$ calculated by the FMI method. Values on ordinate are shown on a logarithmic scale.

values on the ordinate axis. As expected, for all components the standard deviation of the difference between the recordings increases with the level of geomagnetic activity from $0.25-0.50 \mathrm{nT}$ during the most quiet periods $\left(K_{\mathrm{LON}}=0\right)$ up to several $\mathrm{nT}$ for disturbed periods $\left(K_{\mathrm{LON}} \geq 4\right)$. Generally, we 
have the best agreement with THY data, especially during quiet periods, while the largest differences were found with respect to BDV and FUR data. The obvious reason for this is the distance between the observatories. THY is the closest to LON (196 km), followed by HRB $(302 \mathrm{~km})$, GCK $(335 \mathrm{~km})$, BDV $(456 \mathrm{~km})$, and FUR $(514 \mathrm{~km})$. Although HRB is somewhat closer to LON than GCK, the difference between LON and GCK latitudes is smaller than between LON and BDV. Since the geomagnetic variations of external origin (the ionospheric and magnetospheric currents) are latitude-dependent, we have better agreement with GCK data than with HRB data, in all components except in $Y$ during geomagnetically quiet periods. The reason for increased (LON-GCK) values in $Y$ during quiet periods is the greater difference in longitude with respect to other observatories (FUR is the only observatory that has larger longitudinal separation with LON than GCK). In this case, the dominant "solar quiet variation" $\left(S_{q}\right)$ moves with the Sun causing local time or longitude dependence. Furthermore, during higher magnetic activity, the standard deviation (LON-GCK) are close to (LON-THY) in all components. This result is ascribed to the small difference between LON and GCK latitudes, which is the smallest in comparison with other observatories.

To obtain insight into the artificial noise level (and to detect the presence of unnatural spikes, if they exist), the same data series were used to derive rate of change $d B / d t$ time series during very small geomagnetic activity (Mandea and Korte 2011, Worthington et al. 2009).

For purposes of visual impression, the rate of change $d X / d t$ for LON and nearby observatories are shown in Fig. 8. $\dot{X}=d X / d t$ was calculated as simple forward differences of original time series, $\dot{X}=X(i+1)-X(i)$ for $i=1, \ldots, N$, where $N=264960$ is the overall number of minutes from 1 July 2012 at 00:00 UT to 31 December 2012 at 23:59 UT. In addition, the bottom diagram in Fig. 8 shows the values of the indices $K_{\mathrm{LON}}$, where the missing values are denoted by -1 . By visual inspection, one can find great similarity between the data from the different observatories, without spikes that originate from man-made disturbances or problems of the instrumentation. Similar results were obtained for other components. Natural spikes, i.e., increased level of $\dot{X}$, are common for all observatories used in this study. They are directly related to geomagnetic activity and consequently correlated with indices of geomagnetic activity as presented in Fig. 8. It is not so obvious (from Fig. 8) but careful visual inspection reveals an increase in absolute values of the dominant spikes during higher geomagnetic activity for stations with higher geomagnetic latitudes.

Following a similar procedure used to obtain the results presented in Fig. 7, instead of using centred differences, we calculated the average stand- 


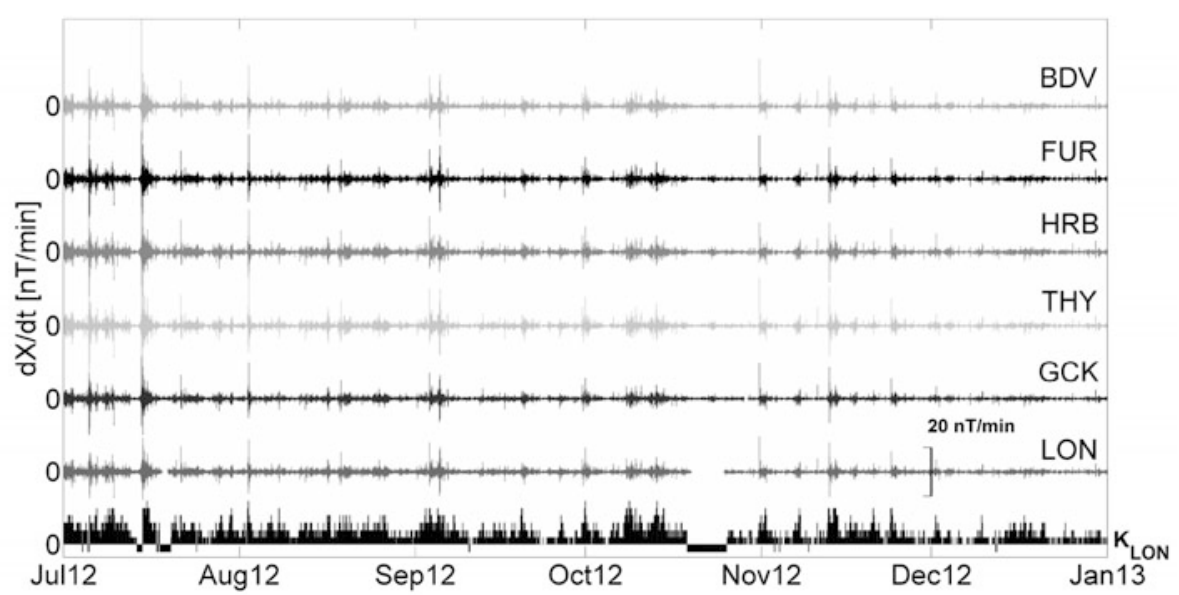

Fig. 8. Rate of change $d X / d t$ at LON and surrounding IMOs calculated from minute data during the second part of 2012. The lowest diagram indicates geomagnetic activity index $K_{\mathrm{LON}}$ for the same period ( -1 denotes missing values).

ard deviations of $\dot{X}, \dot{Y}, \dot{Z}$, and $\dot{F}$ of each observatory. Table 1 presents the average standard deviations for geomagnetically quiet periods $\left(K_{\mathrm{LON}} \leq 2\right)$. The occurrence frequency of these quiet periods is $9.3 \%$ (i.e., $24660 \mathrm{~min})$ for $K_{\mathrm{LON}}=0,29.8 \%(79020 \mathrm{~min})$ for $K_{\mathrm{LON}}=1$, and $30.3 \%$ $(80280 \mathrm{~min})$ for $K_{\mathrm{LON}}=2$. The results in Table 1 clearly show that the noise level (at $0.0167 \mathrm{~Hz}$ ) at LON is the same or lower than that at surrounding IMOs. As expected, for all observatories the magnitudes of natural "noise" are larger for the horizontal components $(X, Y)$ than for the vertical and total intensity. Noise increases with the geomagnetic activity index, as well as with latitude.

\subsection{Multiple linear regression residual analysis}

In many studies, data gaps are not acceptable and they present an obstacle, because many numerical procedures are not designed to handle missing data. Commonly, missing data are replaced by data obtained using some interpolation or extrapolation technique. Here, we must emphasize that the primary task of an observatory is to report the real measured data, together with the data gaps. Any additional manipulations of the data are strictly forbidden. Later, the data users may decide how to use the data according to their needs. Nevertheless, by exploring the correspondence between the time series from neighbouring observatories and LON, we investigated the feasibility of replacing the missing LON data with data obtained by interpolation using multiple linear regression (MLR) analysis. To achieve this goal, we 
firstly investigated which combination of the surrounding observatories gives the smallest MLR residual, and thereafter the best combination was used to analyse MLR interpolation residuals (MLRI). A detailed explanation is given below.

Using the data from the second part of 2012 and various combinations of surrounding IMOs, we firstly determined the average MLR residual versus the maximum of $a k$ index and the average $A k$ index ( $A k$ is the daily mean value of $a k$ indices). In most cases, $A k$ index is different for each day, so we sorted the $A k$ 's into bins with a width of $10 \mathrm{nT}$. Then, the average and related residual for each bin were computed. One example of this procedure (for $Z$ component) is presented in Fig. 9 (left) for the combination L-T-G-H-F (LON-THY-GCK-HRB-FUR). In general, for all combinations we have obtained rather high $(>0.93)$ correlation coefficients $(\mathrm{CC})$ between the average MLR residuals and maximal $a k$, or average $A k$ index. Numerical values of $\mathrm{CC}$ for all combinations are presented in Fig. 9 (right), together with the overall averages of MLR residuals (i.e., means from the left subplot). For all combinations, the slope of the fitted line (Fig. 9, left) is smaller for the residual versus $\max (a k)$, and consequently the overall MLR residuals are smaller (Fig. 9, right). Similar results were obtained for other components. The lowest CCs were obtained for some combinations of the $Y$ components, although they are also relatively high, above 0.8 . Like in $Z$, the MLR residuals for other components have a decreasing trend with an increasing number of observatories that participate in the regression. Residuals also vary from several $\mathrm{nT}$ to a fraction of $\mathrm{nT}$. Based on the results of the above analysis, we decided to use the combination L-T-G-H-B-F to investigate MLRI residuals, because this combination gives the smallest MLR residuals for all components in both cases: MLR residuals versus avg $(A k)$ and MLR residuals
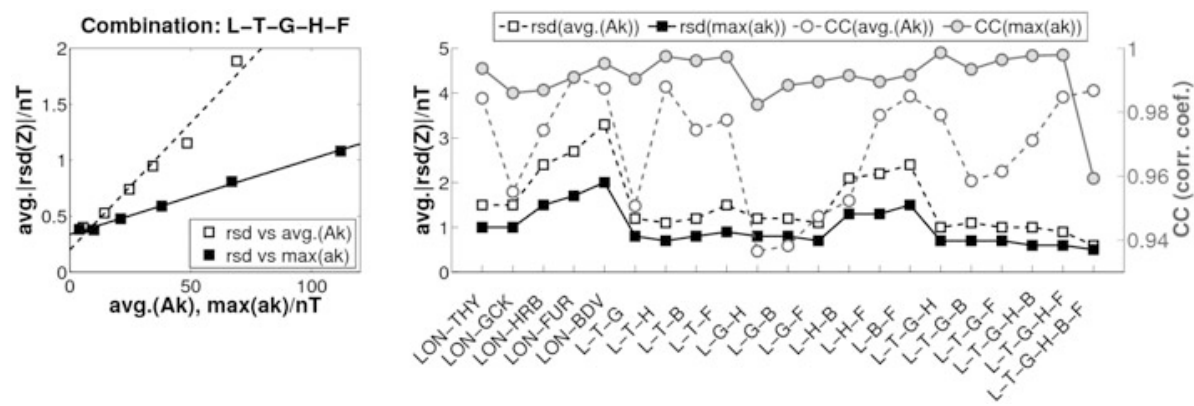

Fig. 9. Left: Example of the average daily regression residual for the vertical component with respect to average $A k$ index and maximum daily $a k$ index. Right: Correlation coefficients between the residuals and indices presented in the left subplot for various combinations (circles) used in regression analysis. Average residuals per combination are denoted with squares. 
versus $\max (a k)$. However, in the case of L-T-G-H-B-F, we can notice the smallest CC versus $\max (a k)$ (Fig. 9, right). After additional investigation the results showed that if one or more observatories is included in the combination L-B-F, the MLR residuals for $\max (a k)=10 \mathrm{nT}$ (equivalent to $K_{\mathrm{LON}}=2$ ) are somewhat smaller than expected. Due this fact, a small degradation in (usually) regular linear trend occurs for L-T-G-H-B-F combination. This means that, in certain situations during low geomagnetic activity, the LON vertical component can be well approximated with BDV-FUR in conjunction with one or more neighbouring observatories. We presume that this is a consequence of the best azimuthal coverage in cases of L-B-F-"other observatory/ies", and the influence associated with the different external variations and their induced effects.

Due to computational reasons, to investigate MLRI residuals we used the minute data from August 2012 only, because this is the period for which LON had complete recordings with no data gaps. The MLRI errors were investigated in various time windows, ranging from $5 \mathrm{~min}$ up to an entire day (1440 min) throughout August. This means that we simulated the missing data in LON time series inside the window, and needed to complement it by interpolation. To find the regression coefficients required for MLR interpolation, we performed a regression analysis using L-T-G-H-B-F combination on the data before and after the simulated data gap. The length of the two subsets, before and after, is equal to the length of the data gap in question, i.e., the series (L-T-G-H-B-F) used to calculate the regression coefficient is twice the size of the gap. Using the regression coefficients and THY, GCK, HRB, BDV, FUR time series, we calculated LON values within the gap. The procedure was repeated starting from 1 August throughout August, where the time windows $(5,10,15 \mathrm{~min}, \ldots$ etc. up to $1440 \mathrm{~min})$ were subsequently shifted. For each time window, the absolute residuals (observed-MLRI calculated) were averaged for entire August, and the average MLRI residuals for various time windows were obtained.

Since magnetic variations on different locations will differ from each other for some time lag (Riddihough 1971), the same treatment was done using THY, GCK, HRB, BDV, FUR time series after correcting, i.e., aligning them for the time lag $\tau$ with respect to LON. The corresponding time lags of the series were determined using cross-correlation analysis (Bendat and Piersol 2000) on a global time scale, i.e., the series for entire August was used to find $\tau$. Additionally, in an analogous manner for the same time windows we calculated the residuals that originate from linear, cubic, and spline interpolation.

Residuals obtained with commonly used interpolation techniques together with MLRI residuals are presented in Fig. 10. MLRI residuals calculated using original time series are denoted with circles and named "regress" in 

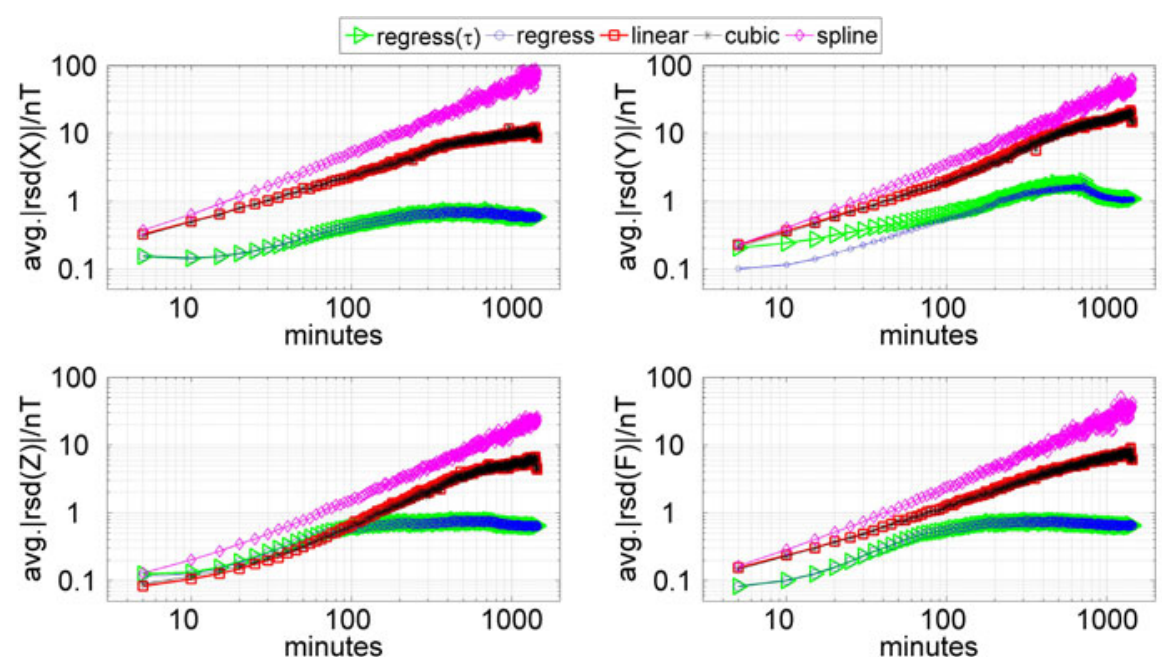

Fig. 10. Average residuals using several interpolation techniques for different interpolation intervals: 5, 10, up to $1440 \mathrm{~min}$ (see text for details). Logarithmic scale is used to present values on the abscissa and ordinate.

the legend in Fig. 10, while MLRI residuals obtained using aligned time series are denoted with triangles and named "regress $(\tau)$ ". Except for the $Z$ component in the case where we simulated shorter data gaps, in all other cases MLRI residuals are smaller than those obtained with standard interpolation techniques. The biggest residuals were obtained using spline interpolation, while linear and cubic interpolations gave practically the same results in all cases. Increased residuals in the spline case are due to the lack of samples within a gap which would constrain the wiggling of splines. Further, spline interpolation (not smoothing splines, to avoid misunderstanding) is more adequate for interpolation problems where we have a rather uniform distribution of samples and missing data. Generally, in interpolation problems the spline performance is also increasing as the ratio between the lengths of interpolation intervals and sampling rate approaches 1 . This is also evident from Fig. 10, where residuals obtained by spline interpolation converge toward linear and cubic residuals as data gaps become shorter. Slightly better results were obtained with linear and cubic interpolation compared to the MLR approach in $Z$ component in the cases when we supposed shorter data gaps, i.e., less than $90 \mathrm{~min}$. This result was partly expected and we attribute it to the effects that originate from induced currents flowing in the conducting Earth (Jankowski and Sucksdorff 1996). This phenomenon is particularly pronounced in the vertical component; it has a local character and is related to the distribution of the ground conductivity in the area surrounding the observatory location. 


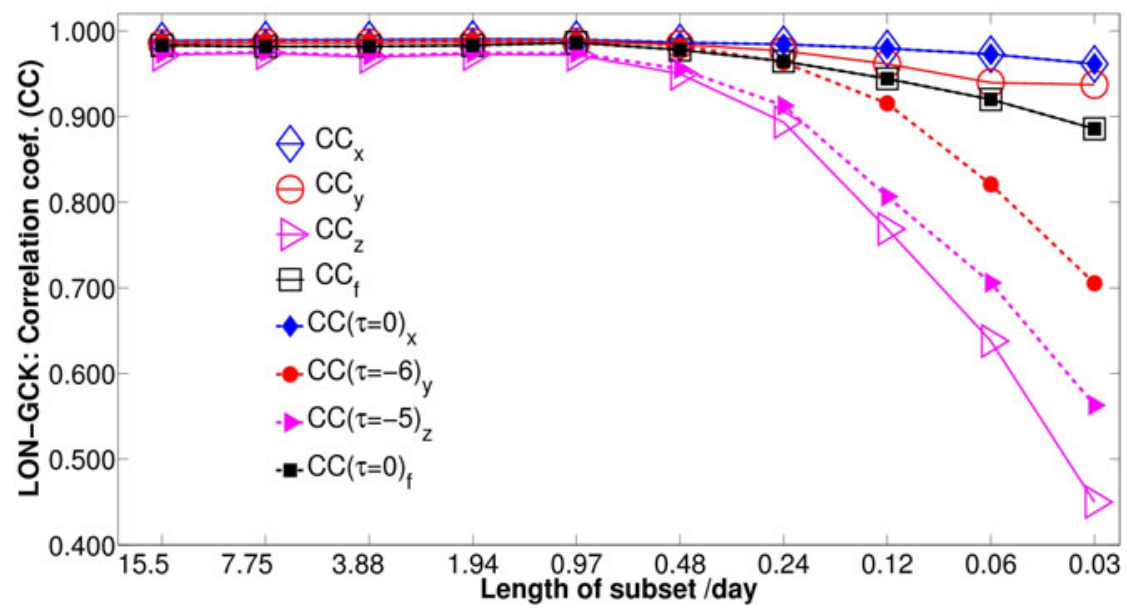

Fig. 11. Average correlation coefficients (CC) for subsets of equal length between LON and GCK, $X, Y, Z$, and $F$ time series. CCs are calculated for pure time series and after adjusting it for the time lag $\tau$. Negative $\tau$ means that LON variations are delayed after GCK variations.

In almost all cases, practically the same results were obtained using MLRI with and without time lag correction. The exception is the $Y$ component, for windows with shorter lengths $(<100 \mathrm{~min})$ the MLRI residuals obtained with time lag correction are higher than those without the correction.

Sensitivity of $Y$ series to the time lag correction can be explained if we investigate the behaviour of CC on global and local time scales. To do this, we calculated the sequence of $\mathrm{CC}$ between LON and observatories for each component. Firstly we divided the time series in two subsets (i.e., 15.5 days) and the mean $\mathrm{CC}$ for both pairs of subsets. These subsets were again divided into four pairs of subsets, each having length of 7.75 days, and the associated CCs were averaged. Thus, we iteratively calculated the average CCs for the pairs of subsets having length equal to floor $\left(L / 2^{n}\right)$, where $L$ is the length of entire time series in August, and $n=1, \ldots, 10$ is the number of iterations. This procedure was done with pure (uncorrected) time series as well as with those corrected for the time lag $\tau$.

Figure 11 presents the average CC between LON and GCK uncorrected and average $\mathrm{CC}(\tau)$ where GCK corrected time series has been used. From the presented diagram, we can conclude that correlation on a global time scale is better than on a local time scale for all components. Furthermore, we can notice significant degradation in correlation for small time scales in $Z$ component, while degradation in $Y$ component occurs only when GCK corrected time series is used. Similar results were obtained with other observatories 
used in this paper. These results unambiguously explain why MLRI errors (Fig. 10) in $Z$ for small time scales $(<90 \mathrm{~min}$ ) are somewhat higher than errors obtained with linear and cubic interpolation. The distinction between $\mathrm{CC}$ and $\mathrm{CC}(\tau)$ in $Y$ component (Fig. 11) clearly shows why MLRI errors obtained with corrected series are much higher than those obtained when using pure, uncorrected time series. The advantage of using uncorrected series over those corrected for the time lag can be ascribed to several contributions: (a) $\tau$ is determined on a global level, i.e., using the series for entire August; (b) the separation between LON and nearby observatories is relatively short $(\leq 500 \mathrm{~km})$; (c) in the summer season, the focus of the northern hemisphere $S_{q}$ (equivalent current system) vortex passes over the Balkan peninsula around the local noon as it moves from east to west as the Earth rotates (Torta et al. 1997); (d) foci paths are very changeable month-to-month. Also, during winter season the $S_{q}$ focus east-west movement occurs over north Africa, between $20^{\circ}$ and $30^{\circ}$ northern latitudes. Due to complexity of the $S_{q}$ system and accompanying induced effects, especially during the summer season, it would be worthwhile to perform the same analysis for other months and with time lags determined on a shorter time scale. However, these investigations are outside of the paper objectives and are left to be done in our future studies.

\subsection{ULF wave observations}

The location of Lonjsko Polje is ideal for ULF wave observations. Due to the man-made electric noises produced by industry, transportation (trams, electric railways, etc.) and even by households (pumps, air conditioners, etc.) it is more and more difficult to find an electromagnetically quiet site in Europe for ULF wave observation. Thanks to the careful selection process, LON is now among the quietest magnetic observatories in Europe (Fig. 12).

The primary goal of EMMA (European quasi-Meridional Magnetometer Array) is to monitor plasmaspheric plasma mass density in near real time by detecting geomagnetic field line resonances (FLRs), i.e., the eigenmodes of geomagnetic field lines. The detection of FLRs is based on the characteristic spatial features of the resonance. FLRs are typically driven by some broad band source ULF wave activity of extra-magnetospheric origin. A part of the energy of these waves propagating across magnetic field lines toward the Earth is resonantly absorbed by FLRs (e.g., Heilig et al. 2013b). Applying the gradient method we can identify the resonance frequency of the field line having its footpoint halfway between two nearby, but latitudinally separated stations. Both phases change rapidly through the resonance. The amplitude ratio is around one and the phase difference maximises at the resonant frequency. In Fig. 13 an example is shown: daily dynamic amplitude ratio (top) 


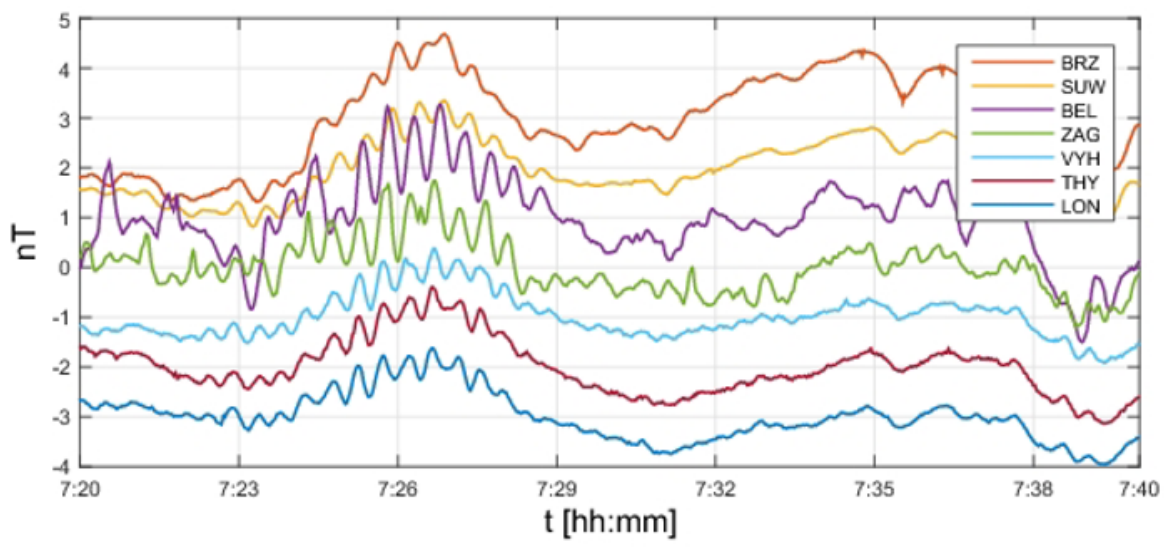

Fig. 12. Stack plot of ULF wave recordings along EMMA on 15 July 2015 between 07:20-07:40 UT. Besides LON and THY the recordings at VHY (Vyhne, Slovakia), ZAG (Zagorzyce, Poland), BEL (Belsk, Poland), SUW (Suwałki, Poland), and BRZ (Birzai, Lithuania) are shown.
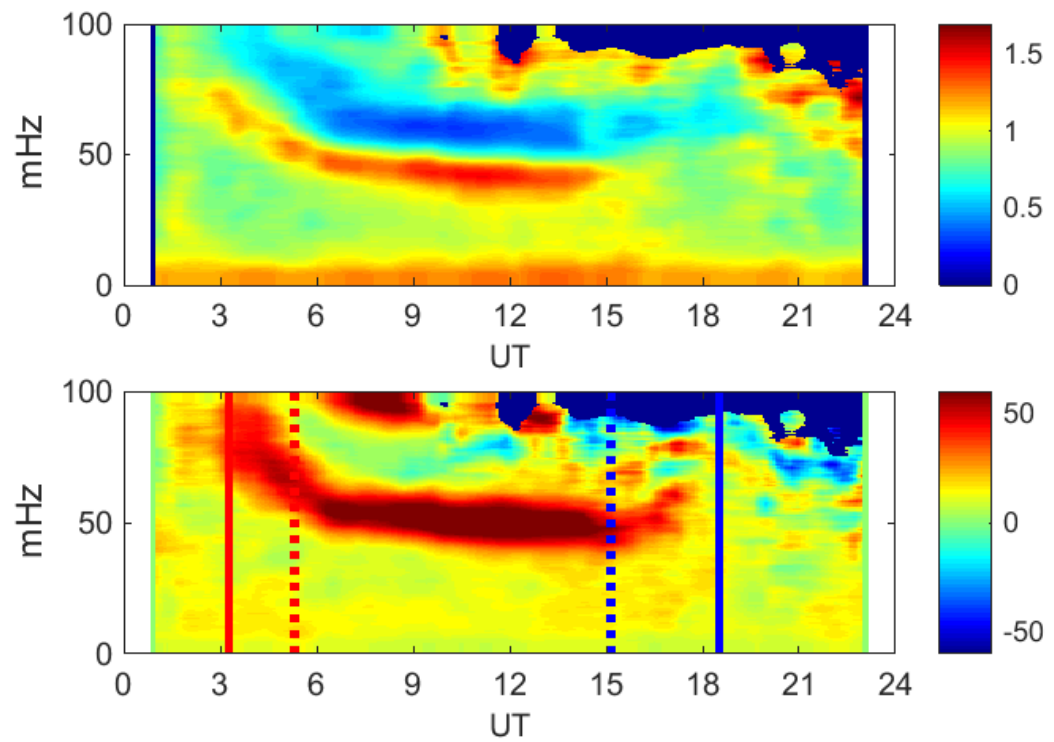

Fig. 13. Amplitude ratio (top) and phase difference (bottom) spectra computed for THY-LON station pair, 11 July 2015.

and phase difference (bottom) spectra for the THY-LON station pair, 11 July 2015. The fundamental resonance frequency is identified by the dark red band in the bottom panel. Sunrise and sunset times are shown as solid red and blue vertical lines. Dashed lines depict the sunrise and sunset times at the geomagnetic conjugate point (footpoint of the field line on the Southern 
Hemisphere). FLR frequency decreases from local sunrise to the conjugate sunrise then it stabilizes around $50 \mathrm{mHz}$. There is a slow gradual decrease during daytime. After the conjugate sunset, the FLR frequency starts to increase again. FLR cannot be detected under night time conditions. All these behaviours are typical for mid latitude FLRs. The fast dawn and gradual daytime frequency decrease corresponds to the daytime refilling of the plasmasphere from the underlying ionosphere. We note that on this day even the second harmonic of the FLR, which is rarely observed at this latitude, is also detected between 06-09 UT and around 12 UT at around $90 \mathrm{mHz}$. The evolution of the FLR can be clearly followed also from the amplitude ratio spectra. At the resonance frequency the amplitude ratio is around one (greenyellow boundary), while below/above this frequency the amplitude ratio is greater (red) / smaller (blue) than one.

Data from LON are routinely used for FLR observations. Data are accessed and processed remotely in near real time (Lichtenberger et al. 2013). FLR frequencies are used to estimate the plasma mass density at the apex of the field line (i.e., in the plasmasphere). Density monitoring is becoming a key part of global space weather monitoring and an important input parameter for many space weather prediction models.

\section{SUMMARY}

The Lonjsko Polje observatory and data acquired in it during 2012.5-2015.0 are presented. Like in many remote, unmanned observatories without active temperature control, high baseline stability cannot be achieved. However, the use of insulation materials and mechanical stability of the suspended dIdD sensor restrained baseline drift within $\pm 2^{\prime}$ and $\pm 1^{\prime}$ for $D$ and $I$, respectively. In the context of orthogonal field components, those drifts correspond to approximately $\pm 13 \mathrm{nT}$ in the horizontal components $(X, Y)$ and $\pm 7 \mathrm{nT}$ in the vertical component. Most observations were performed with satisfactory accuracy, despite the lack of an observer with many years of experience. After rejecting poorly performed observations ( $11 \%$ of total), standard deviations of the differences between observed and adapted base values were $0.14^{\prime}$ and $0.07^{\prime}$ for $D$ and $I$, respectively. If we account an uncertainty of $0.14 \mathrm{nT}$ in reduction of the total field to pillar $\mathrm{A}\left(\Delta F_{F-\mathrm{A}}\right)$, the estimated absolute accuracy of the data is well within INTERMAGNET standards of $5 \mathrm{nT}$. The detailed analysis of the total field difference among the pillars shows negligible diurnal differences in variations, while small residuals in the absolute sense point out the low gradient of the observatory site.

The observed daily mean values and secular trends are quite consistent with values predicted by global models. In general, the main field models overestimate the observed values, while the models of high degree SHE that 
account high resolution lithospheric contribution, underestimate the observed daily means.

In Sections 4.3 and 4.4, special attention is paid to the analysis of the minute mean values of components in the geographic reference frame and the total field. Comparison of the time series for the second part of 2012 between LON and surrounding IMOs gave logical and meaningful results. Generally, the average standard deviations of the residuals (of centred differences) increase with the distance between observatories. These deviations vary from a fraction of $\mathrm{nT}$ in periods of very small geomagnetic activity, and grow exponentially up to several $\mathrm{nT}$ during high geomagnetic activity. MLR analysis performed for the data in August 2012 also resulted with small average (absolute) residuals. In all cases, these residuals were within several $\mathrm{nT}$, and, generally, the residual values declined as the number of observatories used in MLR analysis increased. The exponential relation between $\sigma_{\text {avg }}$ and $K_{\mathrm{LON}}$, and the linearity of MLR residuals versus ak also verifies representativeness of indices of local geomagnetic activity. Interesting results were also obtained from inspection of MLRI residuals. As expected for all components and larger time windows, MLRI residuals are significantly smaller than residuals obtained by linear, cubic, and spline interpolation. Maximal MLRI residuals were obtained for time windows with length around $700 \mathrm{~min}$. These maximal residuals are $1.1 \mathrm{nT}$ in the $Y$ component, while in other components they are even smaller. Due to induction effects in the locally inhomogeneous Earth that has the greatest influence on the $Z$ component, in this case the linear and cubic interpolation have advantage over MLRI on the shorter time windows $(<90 \mathrm{~min})$. Nevertheless, the difference between MLRI and those obtained by standard interpolation techniques are quite small, an order of magnitude of $0.1 \mathrm{nT}$. MLRI analysis with and without correction for the global time lag $\tau$ showed that it is better to use pure uncorrected time series in MLRI, at least in our case where we have relatively short distances among observatories.

Although slightly outside the scope of this paper, it would be interesting to conduct a similar MLRI analysis of the minute data corrected for the local time lag. This means finding the time lag between series for the data before and after each individual time window. Together with such an analysis, it would be worthwhile exploring the results of a similar analysis on hourly and daily data using longer time series. These are the tasks to be done in our future work.

This paper presents recent activities toward setting up the observatory at Lonjsko Polje Nature Park in mid-northern Croatia, and recently acquired data. Though there are still some open questions and obstacles in achieving INTERMAGNET standards, the detailed data analysis affirms the potential of LON to provide high-quality data, and thus to contribute in real-time 
monitoring of the Earth's magnetic field. Thanks to the unique, quiet location, LON data proved to be very valuable also for space weather monitoring by means of detecting ULF field line resonances from which the plasmaspheric mass density can be derived. There is no other station in this latitude range in Europe with comparably low noise level. The start of regular observatory measurements concludes a decade-long effort of the Geophysical Institute toward establishing the observatory as a prerequisite for scientific and professional development of geomagnetism in Croatia along with other geophysical disciplines.

Acknowledgments. We would like to thank anonymous reviewer for constructive suggestions that helped us to improve the quality of the manuscript. Regular observations would not be possible without the dedicated work of M. Barić. The authors are grateful to D. Ptičar and L. Szabados for their great technical support. Prof. M. Brkić and Dr. D. Šugar from Faculty of Geodesy are acknowledged for their help in the determination of the azimuth mark bearing. We thank GEM Systems for assistance in maintenance of instruments. The results presented in this paper rely on data collected at magnetic observatories. We thank the national institutes that support them as well as INTERMAGNET for promoting high standards of magnetic observatory practice (www.intermagnet.org). This study was developed in the scope of the project "Study of the geomagnetic field and heterogeneities of the lithosphere in Croatia" (No. 119-1193086-1314) financed by the Croatian Ministry of Science, Education and Sport. This work was also supported by the Bolyai Scholarship of the Hungarian Academy of Sciences. The installation of the LEMI magnetometer was founded by the European Community's Seventh Framework Programme ([FP7/2007-2013]) under grant agreement No. 263218.

\section{References}

Alldredge, L.R. (1960), A proposed automatic standard magnetic observatory, J. Geophys. Res. 65, 11, 3777-3786, DOI: 10.1029/JZ065i011p03777.

Bartels, J., N.H. Heck, and H.F. Johnston (1939), The three-hour range index measuring geomagnetic activity, J. Geophys. Res. 44, 4, 411-454, DOI: 10.1029/ TE044i004p00411.

Bendat, J.S., and A.G. Piersol (2000), Random Data: Analysis and Measurement Procedures, 3rd ed., John Wiley \& Sons, Inc., New Jersey.

Brkić, M., and D. Šugar (2008), Croatian geomagnetic normal reference field of 2004.5, Geodetski List 62 (85), 1, 1-8. 
Brkić, M., D. Šugar, M. Rezo, D. Marinković, and T. Bašić (2006), Croatian geomagnetic repeat station network. In: J.L. Rasson, and T. Delipetrov (eds.), Geomagnetics for Aeronautical Safety, A Case Study in and around Balkans, Springer Verlag, Dordrecht, 137-143.

Brkić, M., D. Šugar, M. Pavasović, E. Vujić, and E. Jungwirth (2012), Croatian geomagnetic field maps for 2008.5 epoch, Ann. Geophys. 55, 6, 1061-1069, DOI: $10.4401 / \mathrm{ag}-5395$.

Cueto, M., D. McKnight, and M. Herraiz (2003), Daily geomagnetic variations on the Iberian Peninsula, Geophys. J. Int. 152, 1, 113-123, DOI: 10.1046/ j.1365-246X.2003.01826.x.

De Boor, C. (1978), A Practical Guide to Splines, Springer Verlag, New York.

De Boor, C. (2003), Spline Toolbox for Use with MATLAB, The MathWorks, Inc.

Hegymegi, L., B. Heilig, and A. Csontos (2004), New suspended dIdD magnetometer for observatory (and field?) use. In: Proc. 11th IAGA Workshop on Geomagnetic Observatory Instruments, Data Acquisition, and Processing, Kakioka and Tsukuba, Japan, 28-33.

Heilig, B., H. Lühr, and M. Rother (2007), Comprehensive study of ULF upstream waves observed in the topside ionosphere by CHAMP and on the ground, Ann. Geophys. 25, 3, 737-754, DOI: 10.5194/angeo-25-737-2007.

Heilig, B., J. Lichtenberger, M. Vellante, J. Reda, T. Rita, P. Sutcliffe, M. Váczyová, D. Herak, M. Neska, L. Merényi, A. Csontos, P. Kovács, M. Srbecky, and I. Mandić (2013a), EMMA for near real time Monitoring of the Plasma-sphere. In: Proc. 15th IAGA Workshop on Geomagnetic Observatory Instruments, Data Acquisition and Processing, San Fernando, Spain, 127-130.

Heilig, B., P.R. Sutcliffe, D.C. Ndiitwani, and A. Collier (2013b), Statistical study of geomagnetic field line resonances observed by CHAMP and on the ground, J. Geophys. Res. Space Phys. 118, 1934-1947, DOI: 10.1002/jgra.50215.

Jankowski, J., and C. Sucksdorff (1996), Guide for Magnetic Measurements and Observatory Practice, International Association of Geomagnetism and Aeronomy, Boulder, USA.

Lauridsen, K.E. (1985), Experience with the DI-fluxgate magnetometer inclusive theory of the instrument and comparison with other methods, Geophysical Papers R-71, Danish Meteorological Institute, Copenhagen, Denmark.

Lichtenberger, J., M. Clilverd, B. Heilig, M. Vellante, J. Manninen, C. Rodger, A. Collier, A. Jørgensen, J. Reda, R. Holzworth, and R. Friedel (2013), The plasmasphere during a space weather event: first results from the PLASMON project, J. Space Weather Space Clim. 3, A23, 1-13, DOI: $10.1051 / \mathrm{swsc} / 2013045$.

Mandea, M., and M. Korte (2011), Geomagnetic Observations and Models, IAGA Special Sopron Book Series, Springer, Dordrecht, DOI: 10.1007/978-90481-9858-0. 
Markušić, S., D. Herak, and I. Mandić (2012), First Croatian geomagnetic observatory in Lonjsko Polje, Cartography Geoinform. 11, 18, 194-199.

Matsushita, S., and W.H. Campbell (1967), Physics of Geomagnetic Phenomena, Academic Press, New York.

Maus, S. (2010), An ellipsoidal harmonic representation of Earth's lithospheric magnetic field to degree and order 720, Geochem. Geophys. Geosyst. 11, 6, Q06015, DOI: 10.1029/2010GC003026.

Maus, S., S. Macmillan, S. McLean, B. Hamilton, A. Thomson, M. Nair, and C. Rollins (2010), The US/UK world magnetic model for 2010-2015, NOAA Technical Report NESDIS/NGDC, British Geological Survey.

Menvielle, M., N. Papitashvili, L. Häkkinen, and C. Sucksdorff (1995), Computer production of K-indices: Review and comparison of methods, Geophys. J. Int. 123, 3, 866-886, DOI: 10.1111/j.1365-246X.1995.tb06895.x.

Merényi, L., B. Heilig, and L. Szabados (2013), Geomagnetic data acquisition system developed for PLASMON project. In: Proc. 15th IAGA Workshop on Geomagnetic Observatory Instruments, Data Acquisition, and Processing, San Fernando, Spain, 54-56.

Mokrović, J. (1948), K problemu geomagnetizma u FNRJ, Geodetski List 7, 8, 177 186.

Montgomery, D.C., E.A. Peck, and G.G. Vining (2012), Introduction to Linear Regression Analysis, John Wiley \& Sons, Inc., Hoboken.

Newitt, L.R., C.E. Barton, and J. Bitterly (1996), Guide for Magnetic Repeat Station Surveys, International Association of Geomagnetism and Aeronomy, Boulder, USA.

Olsen, N., H. Luhr, T.J. Sabaka, M. Mandea, M. Rother, L. Tøffner-Clausen, and S. Choi (2006), CHAOS - A model of Earth's magnetic field derived from CHAMP, Ørsted, and SAC-C magnetic satellite data, Geophys. J. Int. 166, 1, 67-75, DOI: 10.1111/j.1365-246X.2006.02959.x.

Riddihough, R.P. (1971), Diurnal corrections to magnetic surveys - An assessment of errors, Geophys. Prospect. 19, 4, 551-567, DOI: 10.1111/j.13652478.1971.tb00900.x.

Sabaka, T., N. Olsen, and M. Purucker (2004): Extending comprehensive models of the Earth's magnetic field with Oersted and CHAMP data, Geophys. J. Int. 159, 2, 521-547, DOI: 10.1111/j.1365-246X.2004.02421.x.

Shirman, B.. and B. Ginzburg (2004), Influence of local field inhomogeneity on the accuracy of precise total magnetic field monitoring, Meas. Sci. Technol. 15, 12, 2370-2374, DOI: 10.1088/0957-0233/15/12/003.

Škreb, S. (1912), Elementi zemaljskog magnetizma, Nastavni Vjesnik 20, 6, 436-442.

St-Louis, B. (2011), Intermagnet technical reference manual (Version 4.5).

Thébault, E., C.C. Finlay, C.D. Beggan, P. Alken, J. Aubert, O. Barrois, F. Bertrand, T. Bondar, A. Boness, L. Brocco, E. Canet, A. Chambodut, A. Chulliat, P. Coïsson, F. Civet, A. Du, A. Fournier, I. Fratter, N. Gillet, B. Hamilton, 
M. Hamoudi, G. Hulot, T. Jager, M. Korte, W. Kuang, X. Lalanne, B. Langlai, J.M. Léger, V. Lesur, F.J. Lowes, S. Macmillan, M. Mandea, C. Manoj, S. Maus, N. Olsen, V. Petrov, V. Ridley, M. Rother, T.J. Sabaka, D. Saturnino, R. Schachtschneider, O. Sirol, A. Tangborn, A. Thomson, L. Tøffner-Clausen, P. Vigneron, I. Wardinski, and T. Zvereva (2015), International geomagnetic reference field - the twelfth generation, Earth Planets Space 67, 79, 1-19, DOI: 10.1186/s40623-015-0228-9.

Torta, J.M., J.J. Curto, and P. Bencze (1997), Behaviour of the quiet day ionospheric current system in the European region, J. Geophys. Res. 102, A2, 24832494, DOI: 10.1029/96JA03463.

Verbanac, G., and M. Korte (2006), The geomagnetic field in Croatia, Geofizika 23, 2, 105-117.

Verbanac, G., and E. Vujić (2012), Determination of the Croatian geomagnetic observatory location, Acta Geophys. 60, 2, 337-356, DOI: 10.2478/s11600012-0001-4.

Verbanac, G., M. Korte, and M. Mandea (2009), Four decades of European geomagnetic secular variation and acceleration, Ann. Geophys. 52, 5, 487-503.

Vujić, E., G. Verbanac, V. Vujnović, and A. Marki (2009), Detailed analysis of the geomagnetic ground survey performed in middle-northern Croatia over the time 2003-2005, Stud. Geophys. Geod. 53, 4, 497-517, DOI: 10.1007/ s11200-009-0036-4.

Vujić, E., M. Brkić, and N. Radović (2011), Analysis of Croatian geomagnetic repeat station surveys in 2004 and 2007, Stud. Geophys. Geod. 55, 4, 737753, DOI: 10.1007/s11200-010-9037-6.

Vujnović, V., and K. Marić (2001), An overview of measurement activities in geomagnetism in Croatia, Contrib. Geophys. Geod. 31, 1, 29-32.

Vujnović, V., G. Verbanac, J. Orešković, A. Marki, K. Marić, I. Lisac, and M. Ivandić (2004), Results of the preliminary geomagnetic field strength measurement in the northern part of middle Croatia, Geofizika 21, 1-13.

Worthington, E.W., E.A. Sauter, and J.J. Love (2009), Analysis of USGS onesecond data. In: Proc13th IAGA Workshop on Geomagnetic Observatory Instruments, Data Acquisition, and Processing, U.S. Geological Survey Open-File Report, 262-266.

Yamazaki, Y., K. Yumoto, M.G. Cardinal, B.J. Fraser, P. Hattori, Y. Kakinami, J.Y. Liu, K.J.W. Lynn, R. Marshall, D. McNamara, T. Nagatsuma, V.M. Nikiforov, R.E. Otadoy, M. Ruhimat, B.M. Shevtsov, K. Shiokawa, S. Abe, T. Uozumi, and A. Yoshikawa (2011), An empirical model of the quiet daily geomagnetic field variation, J. Geophys. Res. 116, A10312, 121, DOI: 10.1029/2011JA016487. 